ARTIGOS

ESPAÇO, ECONOMIA E POPULAÇÃO

\title{
SIGNIFICADOS LOCAIS DA COLONIZAÇÃO INTERNA NO NORTE MATO-GROSSENSE
}

\author{
Luciana Schleder Almeida* \\ * Universidade da Integração Internacional da Lusofonia Afro-Brasileira (Unilab), Instituto de Humanidades e \\ Letras, São Francisco do Conde, BA, Brasil
}

\begin{abstract}
Resumo
A consolidação do meio-norte do Mato Grosso como área destacada na produção de soja foi consequência da política de "modernização da agricultura" promovida pelo regime militar nos anos 1970. A rápida transformação da paisagem florestal em lavouras ocorreu como parte de um programa oficial de colonização que arregimentou boa parte de seus agentes em "áreas coloniais" do sul do Brasil habitadas por imigrantes europeus desde o início do século XIX. $A$ análise está baseada em um estudo etnográfico sobre famílias de colonos de trajetórias ascendentes que reivindicam para si o protagonismo na fundação de uma "nova sociedade" na fronteira. O objetivo do artigo é problematizar categorias relacionadas à honra pioneira e sua relação com formas de classificação por origem ou identidade regional: "gaúcho", "cuiabano" e "maranhense". O conteúdo etnográfico demonstra como as formas locais de hierarquização social mobilizam princípios da colonialidade do poder que estrutura historicamente o projeto de sociedade nacional.
\end{abstract}

Palavras-chave

Colonização; Agronegócio; Soja; Honra; Etnicidade. 


\author{
ARTICLES \\ SPACE, ECONOMY AND POPULATION
}

\title{
LOCAL MEANINGS OF INTERNAL COLONIZATION IN NORTHERN MATO GROSSO
}

\author{
Luciana Schleder Almeida* \\ * Universidade da Integração Internacional da Lusofonia Afro-Brasileira (Unilab), Instituto de Humanidades e \\ Letras, São Francisco do Conde, BA, Brazil
}

\begin{abstract}
The consolidation of the Mid-Northern region of the state of Mato Grosso as a key area in the soy production was a consequence of the policy of "modernization of agriculture" promoted by the military regime in the 1970 . The transformation of the forest landscape in fields for crop production was part of a colonialization program that enlisted most of its agents in colonial areas in Southern Brazil, inhabited by European immigrants since the beginning of the 19th century. The analysis is based on an ethnographic study of immigrants' families of ascendant settlers who consider themselves to be part of the process of founding the "new society". This article aims to problematize categories related to pioneer honor and its relationship with forms of classification by origin like "gaúcho", "cuiabano" and "maranhense". The ethnographic content demonstrates how local forms of hierarchy mobilize principles of coloniality of power that historically structure the project of national society.
\end{abstract}

Keywords

Colonization; Agribusiness; Soy; Honor; Ethnicity 


\section{SIGNIFICADOS LOCAIS DA COLONIZAÇÃO INTERNA NO NORTE MATO-GROSSENSE}

Luciana Schleder Almeida

Introdução

O avanço da soja nas Américas segue a trilha aberta pela cana-de-açúcar na construção do sistema de produção agrícola mundial. Os estudos de Sidney Mintz (1996) assinalam como a expansão capitalista opera por meio de cultivos estratégicos e exógenos como açúcar, café, tabaco, índigo, algodão e mais recentemente a soja. Em seus últimos escritos, o autor afirma que a soja é o cultivo paradigmático de um novo estágio da história da agricultura nas Américas (DU BOIS; TAN; MINTZ, 2008).

O grão chegou aos Estados Unidos em meados do século XVIII. Até os anos 1960, a produção de soja estava concentrada nos Estados Unidos (68,7\%) e na China $(23,3 \%)$. Nas últimas décadas, o Cone Sul latino-americano se consolidou como região produtora, concentrando metade da área e da produção global. Para efeito dos estudos sobre a produção de soja, o termo "Cone Sul” se refere a Brasil, Argentina, Paraguai, Bolívia e Uruguai. Entre 1970 e 2010, a área plantada de soja cresceu trinta vezes nos referidos países (WESZ JUNIOR, 2014).

O Brasil desponta como segundo colocado em área e em produção desde os anos 1980. O incremento da produção foi um dos desdobramentos de um conjunto de projetos de colonização interna ou de relações coloniais que ocorrem no interior do Estado-nação nas Américas e que tendem a submeter "minorias ou etnias colonizadas" (CASANOVA, 2007). Em meados da referida década, a produção de soja, que estava concentrada na parte meridional do país, iniciou a expansão para 
o Centro-Oeste, a Amazônia e o oeste baiano. O estado do Mato Grosso ${ }^{1}$ concentra atualmente a produção nacional, ao responder por 28\% dela (EMBRAPA, 2019). As plantações estão situadas hoje no meio-norte, no sudeste (na região de Rondonópolis e Primavera do Leste) e na Chapada dos Parecis, a oeste do rio Xingu.

O discurso oficial difundido pelos meios de comunicação usa o termo fronteira para designar a expansão da sociedade nacional sobre o próprio território, de modo a oferecer ao país novas perspectivas. A presença do Estado é detectada em todos os níveis. Nesse sentido, a fronteira pode ser um conceito estreitamente ligado ao mito fundador de determinada sociedade e à crença numa disponibilidade quase infinita de terras. (AUBERTIN; LÉNA, 1988). A concepção da fronteira enquanto "locus por excelência da terra 'ilimitada”" encontra-se combinada com a visão capitalista de uma riqueza sempre crescente e em acumulação, cuja tônica ideológica tende a ocultar a expropriação dos produtores imediatos (VELHO, 1979).

Este estudo apresenta uma contribuição para a compreensão dos significados locais inerentes à integração de novas áreas aos circuitos do mercado global de commodities, com base no contexto do norte mato-grossense. ${ }^{2} \mathrm{O}$ objetivo do artigo é problematizar categorias ligadas à noção de honra fundada na colonização interna como "fundador" e "agricultor", assim como o uso de categorias de classificação por origem ou identidade regional, como "gaúcho", "cuiabano" e "maranhense". O percurso analítico buscou compreender os elementos da honra e da construção das reputações por meio da observação das formas de sociabilidade que mobilizam famílias de $\operatorname{colonos}^{3}$ com trajetórias ascendentes definidas pelo estabelecimento no Mato Grosso.

Até os anos 1970, a área estudada era coberta por floresta parcamente habitada, pontuada por seringais, garimpos e fazendas de pecuária extensiva. A população preestabelecida de comunidades ribeirinhas e indígenas foi sendo impelida a abandonar seus territórios em virtude de uma série de políticas que tinham como objetivo a fixação de população exógena, oriunda das regiões Sul e Sudeste.

Segundo Tavares dos Santos (1993), para esses programas de colonização os “imigrantes” encontrados na região Sul, em sua maioria descendentes de alemães e italianos, eram os agentes preferenciais da modernização da agricultura. Essa opção oficial revela a atualização da eugenia histórica da política de colonização

\footnotetext{
1. Para este texto, será utilizada como referência a área atual do Mato Grosso, estado que foi desmembrado com a criação do Mato Grosso do Sul em 1977.

2. A pesquisa foi financiada pela Fundação Ford, Capes e CNPq e realizada no âmbito do projeto Sociedade e Economia do Agronegócio, sob a orientação da saudosa Profa. Beatriz Maria Alasia de Heredia.

3. O termo "colono" está sendo usado aqui num sentido genérico em referência à população destinada a ocupar as novas áreas conforme a política de colonização oficial.
} 
brasileira, que, desde o século XIX, tem como projeto o embranquecimento da população com a entrada de migrantes (SEYFERTH, 2001).

O dinamismo da fronteira opera por meio de ocupações territoriais de temporalidades diferentes: "frente de expansão" e "frente pioneira". O contexto analisado se enquadra no segundo tipo. A primeira corresponde à ocupação espontânea de territórios pela perambulação de grupos indígenas, populações residuais ou excluídas das áreas já ocupadas pela pecuária ou pela grande agricultura de exportação; a segunda é relativa à ocupação territorial economicamente organizada tanto por empresas agrícolas como pela agricultura familiar e comercial (MARTINS, 1975).

A observação etnográfica concentrou-se em Lucas do Rio Verde e em Sorriso, dois municípios localizados no eixo da BR-163, também conhecida como Cuiabá-Santarém, no trecho em que ocorre a transição entre os biomas Cerrado e Amazônia. As viagens de campo ocorreram entre fevereiro e julho de 2008 e em setembro de 2010. Foram realizadas 27 entrevistas semiestruturadas, além de registros fotográficos e escritos. Algumas famílias permitiram que eu fizesse visitas frequentes ou me hospedaram por algumas semanas em suas casas. Foram visitadas dezessete casas, das quais nove eram de produtores. As demais pertenciam a uma "classe média urbana” de prestadores de serviço, em boa parte oriundos da região Sul. É importante destacar que mais comumente a residência principal dos produtores se situava na cidade; a casa na fazenda era usada esporadicamente. Tendem a habitar a fazenda os produtores de menor porte que tocam a produção com mão de obra familiar, dispensando a contratação de "funcionários”. As propriedades são geralmente chamadas "fazendas" e, mais raramente, de "empresas”, sobretudo em se tratando das maiores - daí a identificação dos grandes produtores como "agricultores”, “fazendeiros” ou "empresários”. A despeito da variação significativa das áreas (a maior parte das famílias afirmou plantar entre mil e 15 mil hectares, com exceção de uma, que plantava cerca de seiscentos hectares de soja4), os dados levam a crer que o uso de mão de obra familiar impõe à administração dos negócios a lógica do ciclo de vida do grupo doméstico.

O primeiro item, a seguir, apresenta um conjunto de dados que reconstituem a nova configuração social fundada pela política de colonização, de forma a assinalar a tendência à concentração fundiária e a rápida transformação da paisagem. No segundo, verifica-se como desigualdades sociais se encontram articuladas com formas de classificação baseadas na origem ou na identidade regional: "gaúcho", “cuiabano” e "maranhense”. A última seção visa dar corpo ao que os colonos

4. Essas informações sobre área plantada foram obtidas durante as entrevistas, mas não foram verificadas em cadastro oficial. 
chamam de "sociedade" ou às formas de cooperação que mobilizam um conjunto de famílias pelo bem comum, com o propósito de compreender os significados locais da honra pioneira ou explicitar o patrimônio ideológico dos colonos.

\section{Aspectos demográficos e fundiários da área estudada}

Antes da abertura da fronteira, os Kayabi que ocupavam territórios nos rios dos Peixes, Verde e Teles Pires já enfrentavam os ataques e as doenças transmitidas por seringueiros e por colonizadores-fazendeiros mais antigos. Em 1966, os irmãos Villas-Bôas removeram parte dos Kayabi do rio Teles Pires para o Parque do Xingu, considerando que se tratava de um grupo em risco iminente (VALENTE, 2017). As primeiras negociações de terras envolvendo as famílias de colonos ainda confrontariam população indígena, haja vista as inspeções aéreas para conferir se as terras estavam "limpas" (DIAS; BORTONCELLO, 2003). A chegada da BR-163, construída entre 1971 e 1976 pelo $9^{\circ}$ Batalhão de Engenharia e Construção do Exército (o $9^{\circ}$ $\mathrm{BEC})$, executava a política de ocupação das áreas de floresta, tratada como matéria de segurança nacional pelo governo militar sob a justificativa de "vazio demográfico" ou de "deserto verde a ser incorporado pela nação" (SILVA, 1967).

O movimento de expansão da soja reúne um conjunto de elementos que permite comparação com o estudo de Monbeig (1998), realizado nos anos 1940 sobre a expansão do café a partir do Vale do Paraíba em direção a São Paulo e ao norte do Paraná. Nos dois casos, aborda-se a exploração de monocultivos estratégicos associados ao estabelecimento de núcleos urbanos, estradas como principais vetores (ferrovias/rodovias do tipo BR) e sujeição das populações preestabelecidas à subalternização, à expulsão ou à extinção.

A colonização no Mato Grosso, no entanto, é considerada mais dirigida que a de São Paulo. Conforme Oliveira (1981), a retomada da política de colonização nos anos 1970 estava impregnada por uma tentativa do governo de controlar o processo de ocupação da fronteira. Nesse sentido, foram criadas agências estratégicas, como a Superintendência do Desenvolvimento da Amazônia (Sudam) e a Empresa Brasileira de Pesquisa Agropecuária (Embrapa), além da elaboração do Plano de Integração Nacional (PIN), que articulava os ministérios dos Transportes, da Agricultura, do Interior e das Minas e Energia.

Na experiência paulista, a colonização promoveu uma intervenção mais restrita por meio dos Núcleos Coloniais e Áreas de Colonização criados pela Secretaria da Agricultura. O objetivo, conforme o discurso oficial, era o fomento à pequena propriedade, no entanto, na maioria dos casos, revelaram-se como reserva de mão de obra ou como frente pioneira para posterior expansão de culturas de exportação (PAIVA, 2008). Os Núcleos Coloniais e as Áreas de Colonização atraíram populações vindas diretamente da Europa (em especial da Itália e da Espanha) ou, 
eventualmente, do Japão, diferentemente do caso mato-grossense, que mobilizou colonos vindos de outras regiões do próprio território nacional - o que reforça a perspectiva de "colonialismo interno".

O novo impulso à Marcha para o Oeste nos anos 1970 está relacionado a eventos de abrangência global que modificaram a divisão mundial do trabalho (MÜLLER, 1982). A expansão da soja no Brasil e na Argentina e a possibilidade de competir com a produção estadunidense estão relacionadas a mudanças na política de comércio com as Américas durante o governo de Richard Nixon (1969-1974). O contexto da Guerra Fria provocara crescentes déficits na balança de pagamentos dos Estados Unidos e, em 1971, o governo decidiu adotar um sistema de câmbio flutuante que remoldaria o sistema econômico mundial, até então baseado na conversibilidade do ouro em dólar (SERRANO, 2002). A desvalorização da moeda teve como consequência a restrição da exportação do grão desse país, e a decorrente retração criou uma demanda por novas áreas produtoras, o que acabou por fomentar a política de colonização interna brasileira (SOUSA; VIEIRA, 2008).

Fatores relacionados à política econômica doméstica também contribuíram para o crescimento do setor da soja. O desenvolvimento dessa indústria foi considerado estratégico para economizar divisas mediante a substituição de importação, o aumento do recebimento de divisas, a melhoria na dieta nacional, o estímulo ao desenvolvimento industrial, a manutenção dos preços baixos dos alimentos e a ocupação do território nacional (WARNKEN, 1999).

Até os anos 1960, a produção de soja estava concentrada no norte do Rio Grande do Sul e no Paraná. Ao final da década seguinte, com base em incentivos governamentais, ocorreu a expansão sobre o Cerrado. A política econômica do período foi marcada pela liberalidade da política de crédito rural, a abundância de incentivos fiscais e o aporte direto do gasto público na execução das políticas de fomento produtivo e comercial. A criação da Embrapa em 1974 desempenhou papel estratégico no desenvolvimento de tecnologia específica para a produção de soja nessas "novas áreas”.

O padrão de financiamento rural sofreu transformações que influenciaram o ritmo de expansão da soja sobre o Cerrado. Até o final dos anos 1970, havia predominância dos bancos estatais, com taxas de juros orientadas à produção agrícola. As condições macroeconômicas definidas pela violenta alta da taxa de juros e dos preços do petróleo provocaram a retração da capacidade de financiamento e a crescente inserção do sistema de financiamento no domínio das operações privadas do mercado financeiro (DELGADO, 2012).

A produção de commodities agrícolas surgia como forma de compensar a redução da atividade econômica no país e o crescimento da dívida externa. A despeito da notória retração de crédito e da sinalização negativa dos preços internacio- 
nais, a agricultura conseguiu manter um desempenho positivo entre 1980 e 1985. Tais resultados foram atribuídos à maior seletividade dos beneficiários do crédito e à incorporação de novas áreas, especialmente no Centro-Oeste, para o plantio de soja e a consequente capitalização via valorização da terra (MARTINE, 1991).

A arregimentação das famílias para colonizar o Mato Grosso ocorreu nas chamadas “áreas coloniais” da região Sul que haviam sido abertas por imigrantes europeus a partir do século XIX. A segunda geração de imigrantes que vivia nessas áreas nos anos 1970 enfrentava dificuldades para a reprodução social como camponeses em função do parcelamento dos lotes coloniais de cinquenta hectares. Além da propaganda sobre terras planas e baratas em áreas remotas, havia, portanto, fatores de expulsão relacionados a conflitos por terra entre camponeses e entre camponeses e indígenas. A preferência pelos "imigrantes" 5 era justificada pela familiaridade com a mecanização agrícola e com as circunstâncias da frente pioneira (TAVARES DOS SANTOS, 1993).

Para efeito de análise, a chegada de colonos pode ser agrupada em duas levas oriundas da região Sul. A primeira delas durou até meados dos anos 1980 e inclui aqueles que adquiriram glebas e constituíram empresas colonizadoras, exploraram madeira e deram início tanto às experimentações agrícolas como à construção do núcleo urbano. Constituíram uma classe de produtores que não raro exploram também comércio e serviços, além de exercerem ampla influência na política local e regional. Os colonos considerados "fundadores" estão identificados com a cooperação entre as famílias para realizar as primeiras obras de urbanização, como a igreja ou o acesso a serviços de luz elétrica e telefone.

Uma segunda leva de colonos encontrou uma área altamente valorizada e acabou incrementando a classe média urbana junto a famílias da primeira leva que fracassaram na lavoura e partiram para a construção civil, o comércio e a prestação de serviços. A categoria "gaúcho" foi assumida como nova definição de grupo pelos colonos vindos da região Sul, fossem eles fazendeiros, assentados, comerciantes, prestadores de serviço ou profissionais liberais. Oliven (1990) já havia notado que a adesão dos colonos que migraram para o Mato Grosso à identidade "gaúcha" está relacionada à ascensão social conquistada com o deslocamento, por sua vez associada à grande propriedade. Embora as condições de chegada já não sejam tão promissoras, o fluxo migratório do Sul nunca cessou.

Os dados demográficos e fundiários revelam um processo de transformação relativamente veloz. Conforme se vê na Tabela 1, o crescimento da população do

5. No século XIX, "imigrante" era um termo genericamente tomado como "sinônimo de trabalhador, no sentido de que estava no país para substituir o 'braço escravo' ou para produzir alimentos” (SEYFERTH, 1990). 
Mato Grosso apresenta ritmo intenso desde os anos 1970. Para Heredia e Palmeira (2009), esse crescimento demográfico deve-se, basicamente, a movimentos migratórios, em especial da região Sul. O fluxo migratório de trabalhadores egressos de garimpos no norte do Mato Grosso e de outros estados, em particular do Maranhão, também é expressivo, sobretudo a partir dos anos 1990.

\begin{tabular}{lcccccc}
\hline Brasil - & \multicolumn{7}{c}{ População total } \\
\cline { 2 - 7 } $\begin{array}{l}\text { Estado - } \\
\text { Municípios }\end{array}$ & $\mathbf{1 9 7 0}$ & $\mathbf{1 9 8 0}$ & $\mathbf{1 9 9 1}$ & $\mathbf{2 0 0 0}$ & $\mathbf{2 0 1 0}$ & $\mathbf{2 0 1 9}$ (estimada) \\
\hline Brasil & 93.134 .846 & 119.011 .052 & 146.825 .475 & 157.070 .163 & 190.732 .694 & 210.147 .125 \\
Mato Grosso & 598.849 & 1.138 .918 & 2.027 .231 & 2.505 .245 & 3.035 .122 & 3.484 .466 \\
Lucas do Rio Verde & $*$ & $*$ & 6.693 & 19.316 & 45.556 & 65.534 \\
Sorriso & $*$ & $*$ & 16.107 & 35.605 & 66.521 & 90.313 \\
\hline
\end{tabular}

Tabela 1. Variação da população total - Brasil - estado - municípios (1970-2019)

Nota: $\left(^{*}\right)$ O município ainda não havia sido criado.

Fonte: IBGE. Censos Demográficos de 1970, 1980, 1991, 2000 e 2010.

No que tange à estrutura fundiária, esse processo mais recente de colonização do Mato Grosso fomentou o intenso crescimento da área dos estabelecimentos rurais, ao mesmo tempo que manteve estável a concentração na posse de terra, como demonstra a Tabela 2.

\begin{tabular}{|c|c|c|c|c|c|c|c|c|c|c|}
\hline Mato Grosso & \multicolumn{2}{|c|}{1970} & \multicolumn{2}{|c|}{1980} & \multicolumn{2}{|c|}{1995} & \multicolumn{2}{|c|}{2003} & \multicolumn{2}{|c|}{2014} \\
\hline Área total & 17.27 & 1.746 & 34.5 & .550 & 49.83 & 9.631 & 70.40 & .257 & 106.9 & 1.008 \\
\hline $\begin{array}{l}\text { Grupos de área } \\
\text { total (ha) }\end{array}$ & $\mathrm{N}^{\circ}$ & $\begin{array}{l}\% \text { de } \\
\text { área } \\
\text { total }\end{array}$ & $\mathrm{N}^{\circ}$ & $\begin{array}{l}\% \text { de } \\
\text { área } \\
\text { total }\end{array}$ & $\mathrm{N}^{\circ}$ & $\begin{array}{l}\% \text { de } \\
\text { área } \\
\text { total }\end{array}$ & $\mathrm{N}^{\circ}$ & $\begin{array}{l}\% \text { de } \\
\text { área } \\
\text { total }\end{array}$ & $\mathrm{N}^{\circ}$ & $\begin{array}{l}\% \text { de } \\
\text { área } \\
\text { total }\end{array}$ \\
\hline$<10$ & 22.376 & 0,54 & 23.902 & 0,31 & 9.801 & 0,09 & 4.761 & 0,04 & 11.787 & 0,05 \\
\hline $10<100$ & 14.572 & 2,71 & 21.633 & 2,29 & 37.076 & 3,19 & 47.957 & 3,12 & 71.611 & 3,08 \\
\hline $100<1.000$ & 6.351 & 11,6 & 13.273 & 11,75 & 23.861 & 14,52 & 45.705 & 21,66 & 62.921 & 19,78 \\
\hline $1.000<10.000$ & 1.884 & 29,97 & 3.867 & 33,87 & 7.243 & 40,79 & 16.853 & 67,14 & 21.482 & 56,05 \\
\hline$>10.000$ & 294 & 55,18 & 643 & 51,78 & 767 & 41,41 & $251^{*}$ & 8,05 & 744 & 21,04 \\
\hline
\end{tabular}

Tabela 2. Variação do número de estabelecimentos em relação aos grupos de área total (ha) (Mato Grosso, 1970-2014)

Nota: (*) Conforme Cavalcanti e Fernandes (2006), a diminuição das áreas dos imóveis de mais de 10 mil hectares, de 1998 a 2003, pode se dever à portaria do Incra n 558/99, que excluiu os cadastros de proprietários e detentores de grandes imóveis com suspeita de grilagem. O Mato Grosso apresentou 0,6\% dos imóveis inconsistentes de todo o Brasil, representando $17 \%$ da área, campeão do ranking dos estados.

Fonte: IBGE. Censo Agropecuário 1995-1996 e GIRARDI, 2008. 
No período em que foi realizado o trabalho de campo, os dados referentes à estrutura fundiária de Lucas do Rio Verde e Sorriso revelam que os estabelecimentos com mais de 2.500 hectares correspondiam aproximadamente à metade da área dos municípios, como pode ser constatado pelos números da Tabela 3.

\begin{tabular}{lcccccc}
\hline Município & \multicolumn{3}{c}{ Lucas do Rio Verde } & \multicolumn{3}{c}{ Sorriso } \\
\hline Grupos de área total & $\mathrm{N}^{\circ}$ & Área & $\%$ & $\mathrm{~N}^{\circ}$ & Área & $\%$ \\
\hline$<10$ & 61 & 247 & 0,08 & 127 & 460 & 0,04 \\
$10<100$ & 53 & 1.661 & 0,64 & 365 & 10.685 & 1,37 \\
$100<1000$ & 136 & 59.307 & 23,04 & 274 & 120.154 & 15,47 \\
$1000<2500$ & 47 & 72.691 & 28,24 & 131 & 206.562 & 26,61 \\
$<2500$ & 17 & 123.509 & 47,98 & 91 & 438.533 & 56,48 \\
\hline
\end{tabular}

Tabela 3. Número de estabelecimentos agropecuários e respectiva área (ha) - municípios (2006) Fonte: IBGE. Censo Agropecuário 1995-1996 e GIRARDI, 2008.

Nos anos 2000, quando a região Centro-Oeste superou a região Sul na produção nacional de soja, e o Mato Grosso se destacava como o principal estado produtor, a área plantada em Lucas do Rio Verde e em Sorriso atingiu o patamar atual, mantidos o equilíbrio e a quantidade produzida (714 mil toneladas em Lucas do Rio Verde e 1,9 milhão de toneladas em Sorriso), ao passo que o valor da produção tende a aumentar (IBGE). No período do trabalho de campo, a área colhida de soja correspondia a $87,1 \%$ e a $76,8 \%$ da área total de Lucas do Rio Verde e Sorriso, respectivamente (Tabela 4). A participação da agropecuária no PIB dos dois municípios é significativa, sobretudo no município de Sorriso, que, desde 2011, apresenta o maior PIB agropecuário do Mato Grosso, alternando o segundo lugar com Sapezal e Campo Novo dos Parecis. Na última década, Sorriso manteve o primeiro lugar nacional em quantidade produzida de soja e vem se destacando também na produção de milho (IBGE).

\begin{tabular}{lcccc}
\hline Município & $\begin{array}{c}\mathrm{N}^{\circ} \text { total de } \\
\text { estabelecimentos }\end{array}$ & Área total & $\begin{array}{c}\mathrm{N}^{\circ} \text { total de } \\
\text { estabelecimentos (soja) }\end{array}$ & Área colhida \\
\hline Lucas do Rio Verde & 322 & 257.413 & 178 & 224.420 \\
Sorriso & 994 & 776.395 & 398 & 596.658 \\
\hline
\end{tabular}

Tabela 4. Produção de soja - número de estabelecimentos e área colhida (ha) - municípios (2006) Fonte: IBGE. Censo Agropecuário de 2006.

A pujança da atividade agrícola nas cidades visitadas confere prestígio aos "agricultores”, como preferem ser chamados os colonos que se consolidaram como 
grandes produtores. O termo "agronegócio", embora seja amplamente difundido pelas próprias associações de classe desde os anos 1990 para definir o setor da "agricultura”, quase não era mencionado pelos produtores. A tendência era associar o termo a crimes ambientais e "trabalho escravo", conforme veiculado pela imprensa da região Sudeste. Minha imagem construída de jornalista ou ambientalista contribuía para que alguns produtores enveredassem num discurso apologético diante da mera sugestão do tema, evocando a imagem de autossuficiência do "agricultor" como provedor de alimentos para a população das cidades.

O conjunto de tabelas apresentado revela que a transformação da paisagem por meio da produção de commodities agrícolas está associada à concentração fundiária. A emergência de novas formas de hierarquia fundadas na colonização interna, portanto, encontra-se associada à reprodução da desigualdade social.

\section{Expressões da colonialidade do poder}

Foi curioso viajar durante tantas horas pelo Centro-Oeste e encontrar uma cidade com características que remetiam ao Sul do país: os passeios, a arquitetura, a igreja principal em frente à sorveteria, jovens e carros estacionados numa das ruas centrais no final do domingo. A atmosfera de lanchonetes e restaurantes remetia a negócios similares no centro de Porto Alegre tocados por "gringos", termo que qualifica os descendentes de imigrantes italianos oriundos de "áreas coloniais". Os temas usados para as denominações das ruas centrais e das lojas reforçam a identificação com a região Sul e com o pioneirismo.

Na configuração dos municípios visitados, as fazendas circundam o núcleo urbano em que é realizado o acesso à mão de obra, recursos financeiros, aportes jurídicos, insumos, máquinas e assistência técnica. Estudos apontam que esse esquema se repete em outras áreas identificadas com o "agronegócio" ou projeto de modernização em que o lado "agrícola” perde importância em relação a um conjunto de atividades "intersetoriais" e suas formas de gerenciamento (HEREDIA; PALMEIRA; LEITE, 2010). A tendência dessas cidades médias é reproduzir problemas urbanos de cidades maiores, especialmente as desigualdades socioespaciais (ELIAS; PEQUENO, 2006).

O caso de Sorriso é emblemático porque os próprios habitantes a definem como uma cidade "dividida”. A rodovia separa, de um lado, o projeto urbanístico concebido pelos colonos que coincide com o "centro" de ruas asfaltadas e, do outro, os bairros mais pobres identificados com os trabalhadores das fazendas, da construção e de serviços em que os caminhos de terra causam transtornos. Os pequenos 
templos evangélicos, os botecos e as bicicletarias ${ }^{6}$, assim como as casas na cor do reboco destoam da paisagem do centro com prédios bem-acabados, amplos passeios, praças e largas avenidas.

O crescimento dos bairros periféricos ocorreu a partir dos anos 1990, quando a área passou a receber um contingente expressivo de trabalhadores vindos do norte do Mato Grosso - egressos dos garimpos de ouro que haviam sido desativados na região de Peixoto de Azevedo - e de outros estados, principalmente do Maranhão e do Pará. Essa leva de migrantes ocupou a margem oposta da BR-163, nem sempre em terrenos comprados. Parte dos lotes que a empresa Colonizadora mantinha nessa área foram invadidos e posteriormente regularizados pela prefeitura. Um dos aspectos marcantes desses bairros são as numerosas pequenas moradias do tipo "quitinetes" e "peças", além do movimento das duas rodoviárias chamadas "clandestinas" (terminais que operavam com alvará de agência de turismo): aos domingos, a movimentação de chegada do Maranhão toma conta das ruas; nas terças, os ônibus deixam a cidade (PRESTES, 2010).

A percepção da segregação socioespacial da cidade se expressa cotidianamente por meio do uso de categorias ligadas à dicotomia entre "pobre" e "rico" e ao nível de classificação por origem ou identidade regional, como "maranhense" e "gaúcho". A construção dessas categorias, da perspectiva dos colonos, mobiliza um conjunto de elementos diacríticos que constituem fronteiras sociais de modo a subalternizar o outro não somente pela posição no modo de produção, como também pela ideia de raça.

As falas dos colonos marcam veementemente a "divisão" da cidade, no entanto a configuração do núcleo urbano não subscreve essa rigidez discursiva. Existem bairros "maranhenses” localizados em áreas periféricas do lado "gaúcho”. Há algumas famílias "gaúchas” que habitam bairros "maranhenses”. Contudo, o traçado das ruas nos dois lados da rodovia reforça a percepção da segregação espacial: em vez de numerosos acessos à metade "gaúcha" partindo da rodovia, no "outro lado” existem poucas vias de ligação com a BR-163. A beira da estrada é ocupada por armazéns e pavilhões, de forma que não é possível enxergar as habitações desde a rodovia.

Os trabalhadores das fazendas, chamados “peões”, dividem-se em duas categorias principais: "braçais” e "operadores” do maquinário agrícola. A lida com as máquinas é considerada prestigiosa e geralmente é delegada a peões "gaúchos". Dentre as expressões do valor simbólico atribuído às máquinas, cabe destacar o

6. É perceptível que os sulistas evitam o uso da bicicleta em virtude de uma visão estigmatizante de sua utilização pelos trabalhadores do "outro lado". 
costume que têm os meninos "gaúchos" de brincar com miniaturas de máquinas colheitadeiras e o fascínio do público das exposições agropecuárias diante das máquinas de última geração (ALMEIDA, 2017). O nome "maranhense" opera de forma discretiva, associado à ocupação subalterna em que se lê "braçal". O contingente de trabalhadores menos qualificados tende a desempenhar o que é considerado "trabalho braçal”, como "catação de raiz", "capina do algodão", "lida com veneno", chão de fábrica da agroindústria.

Os ramos da construção civil e de serviços também mobilizam expressiva quantidade de mão de obra. A imagem construída do "maranhense" pelos colonos "gaúchos” se expressa por um conjunto de estereótipos indesejáveis ligados à degeneração do núcleo familiar, à sociabilidade violenta, à lascívia e ao desinteresse pelo trabalho. Essa configuração social corrobora a tese da colonialidade do poder ou da persistência da raça na emergência de novas identidades associadas a papéis e lugares do controle do trabalho (QUIJANO, 2005).

Num ponto intermediário, estão os chamados “cuiabanos” ou os naturais do Mato Grosso. A percepção das cidades do agronegócio como expressão de "progresso" se constitui muito em função da comparação com as cidades "mato-grossenses" consideradas estagnadas, como Rosário do Oeste e Nobres, cujo surgimento se deve à atividade mineradora dos séculos XVI e XVII (NAUK, 2012). Diferentemente dos chamados "maranhenses", "cuiabanos” podem pertencer ao rol dos "pioneiros" por ocuparem posições-chave na expansão da fronteira como mediações políticas regionais associadas. No cenário da chegada, costumeiramente descrito pelos colonos como um lugar já ocupado por colonizadores "paulistas" e por “cuiabanos", destacam-se na paisagem apenas botecos à beira da estrada e plantações rudimentares de mandioca (imagem-evidência de que não eram capazes de enxergar o verdadeiro potencial do lugar). No entanto, aqueles não pertencem ao círculo de honra dos colonos "fundadores", o qual implica determinado capital financeiro (garantido pelo Estado) e étnico ("saber trabalhar").

A correspondência entre funções laborais e origem étnica revela a importância de um "lastro cultural e étnico" para ser incluído nesse projeto dominante. A disposição bipartida da população foi estimulada pela Colonizadora Sorriso e por outras formas de controle social dos $\operatorname{colonos}^{7}$ como desejo de construção de barreiras físicas e vigiadas, para impedir a entrada de "nordestinos” no município. Ao mesmo tempo que lotes eram oferecidos a colonos "gaúchos", outros inte-

7. Sobre controle social e acesso à terra na região, ver DESCONSI, C. O controle da lavoura: a construção de relações sociais e a produção de soja entre assentados do meio-norte do Mato Grosso - Brasil. Tese (Doutorado) - Instituto de Filosofia e Ciências Sociais, Universidade Federal do Rio de Janeiro, Rio de Janeiro, 2017. 
ressados eram impedidos de comprá-los em função da origem social e/ou étnica. Foi sobre essa construção social do espaço que ocorreu a expansão das lavouras de soja (FERNANDEZ, 2007).

\section{Etnicidade e honra pioneira}

A construção do espaço urbano como um emblema pioneiro ou como a materialização de um projeto civilizatório está ligada à categoria "sociedade" que define formas de ação coletiva associadas a tipos organizacionais de natureza étnico-religiosa ou baseados na consignação e na autoatribuição dos indivíduos a categorias étnicas. A etnicidade, portanto, assegura unidade efetiva do grupo tanto quanto pressupõe seu caráter constituído na constante reelaboração de fronteiras sociais (BARTH, 1998).

Nas falas de arrogação pioneira, esse termo remete às comissões comunitárias criadas para executar obras e serviços considerados fundamentais para a formação do núcleo urbano, como a construção da igreja e a instalação de luz e de telefone. Ser reconhecido como parte dessas mobilizações corresponde a um vigoroso marcador de distinção social como pioneiro (ROCHA, 2006; MARQUES, 2012; CORDEIRO, 2018). As formas de cooperação comunitária continuam construindo a cidade nas obras de expansão da malha rodoviária de Sorriso. Outro aspecto constante nas formas de arrogação pioneira corresponde à idealização da autonomia comunitária em relação à presença do Estado. Como padrão, as narrativas iniciam-se com referência ao "vazio" e às "dificuldades” ligadas às precárias condições de fixação na área no "começo": a poeira insalubre, a lama, o racionamento de energia, as enormes distâncias percorridas para alcançar uma linha telefônica ou o hospital. A situação inicial se resolve na exaltação das ações da "sociedade”. Embora a colonização interna tenha sido executada como política de Estado por décadas, a autoimagem construída dos colonos, especialmente os que se consideram “agricultores”, remete ao empreendedorismo associado à identidade étnica que se constitui em relação com a sociedade nacional ou sem recurso do Estado brasileiro.

A categoria "sociedade" corresponde a tipos organizacionais identificados com as "áreas coloniais" de origem, como revela a comparação com a "sociedade de capela” descrita por Seyferth (1990). A capela figura como a principal referência para ações coletivas, pois é, ao mesmo tempo, local de culto, sala de aula, salão paroquial, etc. A "sociedade da capela” corresponde a essa entidade que controla toda a atividade comunitária mobilizada nos casos de doença ou para a realização de tarefas diversas, como a construção de moradia para quem vai casar, de escola comunitária, de capela, assim como o conserto de estradas e o abate de animais domésticos. 
As festas de padroeiro que ocorrem nas capelas rurais em Sorriso e em Lucas do Rio Verde, chamadas de "festas de comunidade", são consideradas pelos colonos como uma reprodução das formas de sociabilidade de suas áreas de origem. São festas em que o objetivo é o "bem comum" ou a construção de benfeitorias nas “comunidades", como são denominados esses centros de sociabilidade rural. "Trabalhar" e "ajudar" são as categorias que expressam o pacto comunitário entre as famílias nas "comunidades" e também em ações de caridade promovidas por associações urbanas, como a Maçonaria e o Rotary Club. As formas de cooperação observadas resultam de atribuições formalizadas de papéis sociais ligados à relação homem-mulher, em que a construção das reputações opera com um referencial de honra associada à masculinidade.

O mesmo termo "sociedade" serve igualmente para designar as associações entre pai, filhos e genros, e mais raramente sobrinhos, organizadas como parte das estratégias familiares para avançar na frente pioneira. O pai compra a terra, muitas vezes, sem se transferir de imediato, encarregando os filhos de cumprir a tarefa de "abertura das áreas", com as primeiras experiências de cultivo. A mulher acompanha o marido e os rapazes solteiros fazem visitas às áreas de origem para casar. Com o passar do tempo, os mais velhos podem juntar-se aos filhos no Mato Grosso.

A chegada ao Mato Grosso foi descrita muitas vezes pelos colonos como reedição da trajetória dos pais. Em entrevista, um prestigiado "agricultor"8 de Sorriso afirmou: "Assim como o meu pai saiu do Rio Grande e veio para o Paraná e eu tinha dois anos, o meu filho completou dois anos aqui”. A família figura como unidade capaz de expandir-se espacialmente. Nesse sentido, a trajetória dos colonos é descrita como a efetuação de um projeto em que o propósito é crescer em termos de vida material e da própria família (DESCONSI, 2011; MARQUES, 2015).

O modelo das "sociedades familiares" organiza ainda a administração das fazendas, conferindo aos grupos empresariais do agronegócio um caráter doméstico. As mulheres em geral não são incluídas nas sociedades e também são alijadas das funções eminentemente agrícolas, no entanto tendem a assumir os escritórios das fazendas ou as lojas da família. Os grupos familiares podem formar cooperativas para negociar a aquisição de insumos, o comércio dos grãos e a armazenagem.

O material reunido permite estabelecer relações com etnografias elaboradas entre os anos 1950 e 1970 no âmbito da "área cultural mediterrânea", em que o conceito de honra é central (DI BELLA, 2005; FREEMAN, 1971). O estudo de Di Bella (2005) demonstra como a noção de honra confere sentido ao pacto comunitário na

8. A.B., 55 anos, nascido em Lagoa Vermelha (RS). Morador de Sorriso desde 1981. Entrevista realizada em sua residência em 24 de maio de 2008. 
Sicília tradicional: ela corresponde a algo herdado da família que pode ser creditado ou esvaziado conforme a conduta individual. A honra individual e a coletiva garantem a manutenção dos vínculos comunitários. Os elementos que constituem a honra do grupo são a castidade das mulheres, a pureza de sua genealogia, a coragem dos homens no campo de batalha, a generosidade para com pobres e estrangeiros.

As festas de comunidade são momentos em que é possível observar como essas formas de participação configuram processos de simbolização em que o pequeno grupo que compõe a comissão acaba por encarnar a comunidade (FREEMAN, 1971). A cada dois anos, é eleita uma "diretoria de igreja” composta de presidente, vice-presidente e tesoureiro, preferencialmente pessoas que moram nas fazendas, geralmente homens de uma das famílias de proprietários de terra. A família que constitui a "diretoria” e os vizinhos solidários (incluindo os proprietários que moram na cidade) assumem as tarefas para a realização da festa.

As comissões formadas preferencialmente por proprietários, casados e católicos (há uma minoria de famílias luteranas no colonato), engajam as mulheres da família por contágio e os funcionários da fazenda. A capela e um pavilhão compõem os centros de sociabilidade rural que mobilizam "patrões” e "peões gaúchos". Nos dias de semana, também ocorrem reuniões na comunidade, depois do expediente, em função dos jogos; as mulheres, entretanto, não costumam participar. Nos finais de semana, os homens reúnem-se para jogar futebol e bocha (um jogo de bolas praticado nas áreas de origem) e, nessas ocasiões, as mulheres comparecem, mas preferem os jogos de cartas e a conversa regada a chimarrão, bebida associada ao "gauchismo".

Os pavilhões também podem ser usados para a comemoração de aniversários ou de bodas. Mensalmente, o padre se desloca da cidade para celebrar missas nas capelas. Trata-se de um dos raros momentos em que as mulheres assumem certo protagonismo, quando as esposas de proprietários locais se dedicam à leitura de textos litúrgicos. O padre desempenha o papel de mediador dos interesses da comunidade. Assim que o ritual litúrgico termina, segue a "hora dos avisos", quando então são discutidos assuntos de interesse da vizinhança, como transporte escolar, catequese, obras, festas.

Nas "festas de comunidade", as funções femininas têm como lugar específico a cozinha localizada no interior do pavilhão. As demais funções são assumidas pelos homens, eventualmente compartilhadas com as mulheres, com exceção da preparação do churrasco, realizada do lado de fora ao ar livre e cujo consumo é o ponto culminante da festa. $\mathrm{O}$ assado ou "churrasco", inclusive, é o alimento identificado com os "gaúchos" como sinal diacrítico em oposição ao gosto pelo peixe dos “cuiabanos” e pela farinha dos "maranhenses". 
Essas performances públicas são reveladoras da associação entre honra pioneira e masculinidade, na medida em que dramatizam papéis sociais, especialmente a oposição entre papéis sexuais. A circulação do assado e dos doces, comida e não comida, opera inversões simbólicas que demarcam estruturas morais do "bom cristão" e sua relação com o discurso pioneiro do "desbravamento" ou do confrontamento da civilização com a floresta. O ímpeto viril exaltado no civismo pioneiro se opõe à natureza selvagem da floresta e seus habitantes, a mata "virgem" - tal qual a castidade feminina.

Conforme Sahlins (1969), o fluxo de determinados bens é especial: a comida consiste num bem que estabelece um circuito próprio, muito em função de seu valor de uso, de sua universalidade. A vida comunal constrange seus membros a realizarem uma série de trocas específicas, portanto, trata-se de um fluxo de bens constrangido por determinada etiqueta. A forma como as pessoas se envolvem com as trocas dessa natureza fornece informações sobre pertencimentos e reputações e também contribui para que eles sejam elaborados -, além de expressar processos de mudança. A noção de reciprocidade é o que permite ler o significado local desse fluxo de bens. As questões levantadas abordam as continuidades ou persistências na maneira de pensar, especialmente quando se consideram a relação homem-mulher e os diferentes papéis atribuídos aos sexos como elementos inerentes à política da honra ou à natureza do pacto assumido pelas famílias engajadas na construção de uma "nova sociedade".

Segundo Lévi-Strauss (2006, p. 431):

“[...] o alimento se apresenta aos homens em três principais estados: pode estar cru, cozido ou podre. Em relação à culinária, o estado de cru constitui o polo não marcado, enquanto os dois outros o são fortemente, mas em direções opostas, o cozido como transformação cultural do cru e o podre como sua transformação natural. Assim é possível discernir uma dupla oposição, subjacente ao triângulo principal, entre elaborado/não elaborado de um lado, e cultura/natureza, do outro" (grifos no texto original).

O assado e o ensopado correspondem aos modos fundamentais de cozido em muitas culturas, em que o assado é colocado do lado da natureza por ser transformado diretamente em contato com o fogo, sem a mediatização da água e do recipiente. Ao mesmo tempo, o assado encarna a ambiguidade de cru por dentro e cozido por fora, natureza e cultura.

Nas "festas de comunidade", as performances públicas dos papéis sexuais opõem o assado e os bolos doces, que são leiloados logo após o almoço. No momento do rito de comensalidade, portanto, o masculino está do lado da natureza 
e o feminino do lado da cultura, identificada com um alimento superelaborado ou sacralizado pela transformação das mulheres, no caso das prendas. Considerando que a honra masculina está associada ao pioneirismo como projeto civilizatório, as festas promovem essa inversão, evidenciando a moralidade dos colonos.

\section{Considerações finais}

Du Bois, Tan e Mintz (2008), no tocante às fazendas de soja nas Américas, consideram que aqueles que são seus proprietários e as administram, embora se preocupem de modo geral com o sucesso da colheita e do processamento, têm no mercado seu maior interesse. A análise demonstra como a financeirização da atividade agrícola acentua essa dissociação com a vida rural. A ambientação árida da sojicultura, composta de estruturas metálicas dos armazéns, de maquinário sofisticado, das rotinas urbanas relacionadas aos negócios, do corpo pouco atlético dos plantadores, do gosto por morar na cidade, contribui para provocar essa sensação de deslocamento, de modo que causou estranheza a preferência dos produtores por serem chamados "agricultores".

O processo de urbanização ocupa posição central na construção da honra pioneira, na medida em que é interpretado pelos colonos como resultado da eficiência de suas formas de organização comunitária, permanentemente atualizadas em performances públicas. Essa visão sobre a fundação das cidades tende a obliterar os recursos do Estado que conduziram os colonos à área baseados na idealização da autonomia comunitária.

\section{Referências}

ALMEIDA, L. S. Na festa, no escritório, na cabine do trator: notas sobre o comércio de insumos agrícolas no "agronegócio" da soja”. Política e Sociedade, v. 16, n. 35, p. 380-402, 2017.

AUBERTIN, C.; LÉNA, P. Apresentação. In: AUBERTIN, C. Fronteiras. Brasília: UnB, 1988. p. 11-15.

BARTH, F. Grupos étnicos e suas fronteiras. In: POUTIGNAT, P.; STREIFF-FENART, J. Teorias $d a$ etnicidade. São Paulo: Ed. da Unesp, 1998. p. 183-227.

CASANOVA, P. G. Colonialismo interno (uma redefinição). In: BORÓN, A. et al. A teoria marxista hoje. São Paulo: Clasco, 2007. p. 431-458. Disponível em: http://bibliotecavirtual.clacso.org.ar/clacso/formacion-virtual/20100715084802/cap19.pdf. Acesso em: 21 fev. 2018.

CAVALCANTI, M.; FERNANDES, B. M. Formação territorial, agronegócio e atuais mudanças na estrutura fundiária de Mato Grosso. Revista Nera, ano 9, n. 8, p. 109-121, 2006.

CORDEIRO, M. S. S. Pioneiros, fundadores e aventureiros - a ocupação de terra em Rondônia. Revista de Antropologia, v. 61, n. 1, p. 125-146, 2018. 
DELGADO, G. C. Do capital financeiro na agricultura à economia do agronegócio. Porto Alegre: Editora da UFRGS, 2012.

DESCONSI, C. Pequenos proprietários rurais: trajetórias de migrantes do Sul do Brasil para o Mato Grosso. Rio de Janeiro: E-papers, 2011.

DIAS, E. A.; BORTONCELLO, O. Resgate histórico do município de Sorriso. Cuiabá: Print Express, 2003.

DI BELLA, M. P. Name, blood and miracles: the claims to renown in traditional Sicily. In: PERISTIANY, J. G.; PITT-RIVERS, J. Honor and grace in Anthropology. Cambridge: Cambridge University Press, 2005.

DU BOIS, C.; TAN, C.; MINTZ, S. Introduction: the significance of soy. In: DU BOIS, C.; TAN, C.; MINTZ, S. The world of soy. Chicago: University of Illinois Press, 2008. p. 1-23.

ELIAS, D.; PEQUENO, R. Desigualdades socioespaciais nas cidades do agronegócio. Revista Brasileira de Estudos Urbanos e Regionais, v. 9, n. 1, p. 25-39, maio 2007.

EMBRAPA. Empresa Brasileira de Pesquisa Agropecuária. Soja em números. Disponível em: https://www.embrapa.br/soja/cultivos/soja1/dados-economicos. Acesso em: 30 ago. 2019.

FERNANDEZ, A. J. C. Do Cerrado à Amazônia: as estruturas sociais da economia da soja em Mato Grosso. 2007. Tese (Doutorado) - Programa de Pós-graduação em Desenvolvimento Rural, Universidade Federal do Rio Grande do Sul, Porto Alegre, 2007.

FREEMAN, S. T. Neighbors: the social contract in a Castilian Hamlet. Chicago: University of Chicago Press, 1971.

GIRARDI, E. P. Atlas da questão agrária brasileira. Presidente Prudente: Unesp: Nera, 2008. Disponível em: http://www.atlasbrasilagrario.com.br/_atlas_/incra-X-ibge/. Acesso em: 30 ago. 2019.

HEREDIA, B.; PALMEIRA, M. Migrações em áreas de agronegócio. Travessia - Revista do Migrante, n. 65, set.-dez. 2009.

HEREDIA, B.; PALMEIRA, M.; LEITE, S. P. Sociedade e economia do "agronegócio" no Brasil. Revista Brasileira de Ciências Sociais, v. 25, n. 74, p. 159-196, out. 2010. Disponível em: http://www.scielo.br/pdf/rbcsoc/v25n74/a10v2574.pdf. Acesso em: 30 ago. 2019.

IBGE. Instituto Brasileiro de Geografia e Estatística. Censos Agropecuários de 1995-1996 e 2006. Disponível em: https://biblioteca.ibge.gov.br/. Acesso em: 30 ago. 2019.

. Censos Demográficos de 1970, 1980, 1991, 2000 e 2010. Disponível em: https://cidades. ibge.gov.br/brasil/mt/panorama. Acesso em: 30 ago. 2019.

Cidades@. Disponível em https://cidades.ibge.gov.br/brasil/mt/sorriso/pesquisa/14/10193?tipo=ranking\&indicador=10368. Acesso em 30 ago. 2019.

Produção Agrícola Municipal. Disponível em https://sidra.ibge.gov.br/tabela/1612. Acesso em 30 ago. 2019.

LÉVI-STRAUSS, C. A origem dos modos à mesa: Mitológicas 3. São Paulo: Cosac Naify. 2006.

MARQUES, A. C. Movimentos em família. Ruris, v. 9, n. 1, p. 13-37, 2015.

Pioneiros de Mato Grosso e Pernambuco. Novos e velhos capítulos da colonização no Brasil. Revista Brasileira de Ciências Sociais, v. 28, n. 83, 2012. 
MARTINE, G. A trajetória da modernização agrícola: a quem beneficia? Lua Nova, n. 23, 1991.

MARTINS, J. de S. Capitalismo e tradicionalismo. São Paulo: Livraria Pioneira, 1975.

MINTZ, S. Dulzura y poder. México: Siglo XXI, 1996.

MONBEIG, P. Pioneiros e fazendeiros de São Paulo. São Paulo: Hucitec, 1998.

MÜLLER, G. O CAI brasileiro e as transnacionais e o CAI soja/indústria das oleaginosas. Relatório 24. São Paulo: Eaesp/FGV, 1982.

NAUK, M. de J. A capitania de Mato Grosso: história, historiografia e fontes. Revista Territórios \& Fronteiras, Cuiabá, v. 5, n. 2, jul.- dez. 2012.

OLIVEIRA, L. R. C. de. Colonização e diferenciação: os colonos de Canarana. 1981. Dissertação (Mestrado) - Programa de Pós-graduação em Antropologia Social, Museu Nacional, Universidade Federal do Rio de Janeiro, Rio de Janeiro, 1981.

OLIVEN, R. G. A tradição revisitada: a (re)construção da identidade gaúcha no Brasil moderno. In: MATO, D. (org.). Teoria y política de la construcción de identidades y diferencias en America Latin y el Caribe. Caracas: Nueva Sociedad, 1994.

PAIVA, O. A política de colonização em São Paulo. Sociedade em Debate, 14 (2): 35-53, 2008.

PRESTES, C. A. Os trabalhadores e a formação de uma cidade do Mato Grosso: família, vizinhança e compadrio em Sorriso. 2010. Dissertação (Mestrado) - Instituto de Filosofia e Ciências Sociais da Universidade Federal do Rio de Janeiro, Rio de Janeiro, 2010.

QUIJANO, A. Colonialidade do poder, eurocentrismo e América Latina. In: LANDER, E. (org.). A colonialidade do saber: eurocentrismo e ciências sociais. Perspectivas latino-americanas. Buenos Aires: Clacso, 2005. Disponível em: http://bibliotecavirtual.clacso.org.ar/ clacso/sur-sur/20100624103322/12_Quijano.pdf. Acesso em: 7 ago. 2019.

ROCHA, B. N. "Em qualquer chão: sempre gaúcho!”: a multiterritorialidade do migrante gaúcho no Mato Grosso. 2006. Dissertação (Mestrado em Desenvolvimento, Agricultura e Sociedade) - Instituto de Ciências Humanas e Sociais, Universidade Federal Rural do Rio de Janeiro, Rio de Janeiro, 2006.

SAHLINS, M. On the sociology of primitive exchange. In: BANTON, M. (ed.). The relevance of models for Social Anthropology. London: Tavistock, 1969. p. 139- 186.

SANTOS, J. V. T. dos. Matuchos: exclusão e luta: do sul para a Amazônia. Petrópolis: Vozes, 1993.

SERRANO, F. Do ouro imóvel ao dólar flexível. Economia e Sociedade, v. 11, n. 2(19), p. 237-253, 2002.

SEYFERTH, G. Colonização, imigração e a questão racial no Brasil. ENCONTRO ANUAL DA ANPOCS, 25, 2001, Caxambu. Disponível em: https://www.anpocs.com/index.php/encontros/papers/25-encontro-anual-da-anpocs/st-4/st10-3/4610-gseyferth-colonizacao/file. Acesso em: 10 mar. 2020.

. Imigração e cultura no Brasil. Brasília: Ed. da UnB, 1990.

SILVA, G. do C. e. Geopolítica do Brasil. Rio de Janeiro: José Olympio, 1967. 
SOUSA, I. S. F. de; VIEIRA, R. de C. M. T. Soybeans and soy foods in Brazil, with notes on Argentina: sketch of an expanding world commodity. In: DU BOIS, C.; TAN, C.; MINTZ, S. The world of soy. Chicago: University of Illinois Press, 2008. p. 234-256.

VALENTE, R. Os fuzis e as flechas: história de sangue e resistência indígena na Ditadura. São Paulo: Companhia das Letras, 2017.

VELHO, O. G. Capitalismo autoritário e campesinato. Rio de Janeiro: Difel, 1979.

WARNKEN, P. F. A influência da política econômica na expansão da soja no Brasil. Revista de Política Agrícola, v. 8, n. 1, 1999.

WESZ JUNIOR, V. J. O mercado da soja e as relações de troca entre produtores rurais e empresas no sudeste de Mato Grosso (Brasil). 2014. Tese (Doutorado) - Programa de Pós-graduação de Ciências Sociais em Desenvolvimento, Agricultura e Sociedade, Universidade Federal Rural do Rio de Janeiro, Rio de Janeiro, 2014. 


\section{Luciana Schleder Almeida}

Graduada em Ciências Sociais, com mestrado e doutorado em Antropologia. Atualmente é professora adjunta do Instituto de Humanidades e Letras da Universidade da Integração Internacional da Lusofonia Afro-Brasileira (Unilab) e pesquisadora associada do Grupo de Pesquisa em Legislativo, Eleições e Democracia (LED) da mesma instituição. Também é pesquisadora associada do Núcleo de Antropologia da Política (NuAP), ligado ao Programa de Pós-graduação em Antropologia Social do Museu Nacional (UFRJ).

Email: luciana.almeida@gmail.com

ORCID: 0000-0002-4800-7602

Submissão: 16 de maio de 2020.

Aprovação: 23 de novembro de 2020 .

Como citar: ALMEIDA, L. S. Significados locais da colonização interna no norte mato-grossense. Revista brasileira de estudos urbanos e regionais. v. 23, E202101, 2021. DOI 10.22296/2317-1529.rbeur.202101

Artigo licenciado sob Licença Creative Commons CC BY 4.0.

https://creativecommons.org/licenses/by/4.o/deed.pt_BR 